\title{
Special Considerations for Mass Violence Events in Senior Living Facilities: A Case Report on the Pinelake Health and Rehab Center Shooting
}

\author{
Cody Martin, MS, NRP; David Powell, MPA, EMT-I
}

\section{ABSTRACT}

The 2009 Pinelake Health and Rehab Center shooting in Carthage, North Carolina, presents a unique case study for examining the specific considerations for mass violence events in senior living facilities. A variety of factors, including reduced sensory perception, reduced mobility, and cognitive decline, may increase the vulnerability of the populations of senior living facilities during mass violence events. Management of response aspects such as evacuation, relocation, and reunification also require special consideration in the context of mass violence at senior living facilities. Better awareness of these vulnerabilities and response considerations can assist facility administrators and emergency managers when preparing for potential mass violence events at senior living facilities. (Disaster Med Public Health Preparedness. 2017;11:150-152)

Key Words: mass violence, frail elderly, senior care

T he recent mass violence events in San Bernardino, California, and Sagamihara, Japan, have resurfaced concerns over health care workers and patients being prioritized as soft targets by those desiring to exploit vulnerable populations to inflict large numbers of casualties. Populations often overlooked in mass violence research are institutionalized frail elders and older adults suffering from health conditions, who have greater dependence on others. ${ }^{1}$ Although the majority of mass shootings occur in places of business or educational institutions where frail elders are not disproportionately affected, there are notable exceptions. One poignant example of mass violence targeting elders is the March 2009 shooting at a skilled nursing facility in the town of Carthage, North Carolina.

Although research has been conducted into the effects of disasters on elders and on response to mass violence events, research on vulnerabilities and response to mass violence at senior care facilities is limited. Much of the research on mass violence has focused on responses in educational institutions or office buildings, where $70 \%$ of active shooter events occur. ${ }^{2}$ Given the specific vulnerabilities of elders, this study aimed to use the Pinelake Health and Rehab shooting as a case study to identify areas of special consideration for medical response to potential mass violence events at elder care centers. Key areas of focus included the unique vulnerabilities of elders at elder care facilities and how these affect the medical response to mass violence events.

\section{REPORT: INCIDENT OVERVIEW}

On Sunday morning of March 29, 2009, a gunman walked into the Pinelake Health and Rehab facility in Carthage, North Carolina, and opened fire, killing 7 patients and a nurse and injuring 3 others. The facility housed beds for 110 patients, including 20 beds dedicated to patients with Alzheimer's disease. Prior to the shooting, Pinelake Health and Rehab had a "much above average" overall rating from Medicare and was not known to be a problem to local fire inspectors or emergency medical services (EMS) responders (S Brooks, unpublished interview, November 2016). ${ }^{3}$ The patients killed ranged in age from 75 to 98 years. $^{4}$

The gunman's selection of the facility was predominantly due to it being the workplace of his estranged wife rather than its housing of vulnerable elderly populations. However, the targeting of individuals at the facility was indiscriminate and disproportionately impacted the facility's elderly patients. The impact of the attack was likely reduced owing to a quick and decisive response by local authorities. Within 4 minutes of the initial 911 call, Justin Garner, the lone Carthage police officer on duty that day, arrived on scene and engaged the gunman. Officer Garner was injured in an exchange of gunfire before he shot and eventually detained the gunman. Local EMS and fire resources arrived 1 minute after the gunman was subdued. The attack lasted 10 minutes from the initial 911 call to the scene being secured. ${ }^{5}$ 
The vulnerabilities of frail elders to disasters such as the events in Carthage have been explored in a number of notable studies. However, despite measureable increases in mass violence, ${ }^{1,6,7}$ these vulnerabilities have not been adequately studied with reference to mass violence. ${ }^{2}$ Furthermore, the percentage of the US population defined as "elderly"1 mandates that the public health community understand the specific risks of the elderly to mass violence.

\section{DISCUSSION \\ Threat Detection}

As with most emergency situations, prompt detection of the hazardous condition is key to those at risk having the necessary time to take protective actions. Mass violence events are no exception. The incipient stages of an active shooter event are marked by auditory warning signs such as gunshots or shouting, which provide the first indications of a threat. These auditory warning signs may not be as quickly detected by the frail elderly owing to a high incidence of hearing impairment in this population. Nearly two-thirds of adults aged 70 years and older exhibit hearing impairment. ${ }^{8}$ The average age of the patients killed at Pinelake Health and Rehab was 85 years of age, ${ }^{9}$ and according to the National Center for Health Statistics, most assisted-living patients are 85 years or older. ${ }^{10}$ Given the high prevalence of hearing loss among the elderly, hearing impairment likely played a role in limiting early hazard detection during the shooting at Pinelake Health and Rehab. Hearing impairment among elderly populations decreases the likelihood of quickly identifying typical auditory cues to active threats, which may decrease the time available for this population to implement protective actions.

\section{Threat Response}

Owing to a higher incidence of reduced auditory sensitivity, senior residents of eldercare facilities may be slower to recognize a hazard and therefore have less time to respond than do younger demographics. Similarly, the higher incidence of cognitive impairment among institutionalized frail elders may reduce their ability to accurately identify and process a threat. Protective actions in and of themselves can also be a challenge. The accepted active-shooter protective actions for the layperson are often summarized in the adage "run, hide, fight." 11 This means that during an ongoing threat from a shooter, one should try to run away, and if this is not possible, to hide or as a last resort to engage the shooter with physical force. These tasks may be particularly difficult for the frail elderly as three-quarters of those over 80 years of age report having a significant disability. ${ }^{1}$ These disabilities can seriously impede a patient's ability to move quickly to run or hide and certainly reduce the ability to fight. Elderly populations generally ambulate slower than do younger populations, and those in residential facilities have a higher prevalence of balance impairment and reduced grip strength. ${ }^{12,13}$ These factors alone may limit the ability of frail elders to quickly evacuate, move to a hiding place, or fight a shooter.

Further confounding these difficulties are cognitive impairments that disproportionately affect the elderly and can lead to confusion and delayed or inappropriate action when faced with a threat. Dementia affects $13.9 \%$ of Americans over 71 years of age, and Alzheimer's disease affects $9.7 \%$ of those in the same age range. Forty-two percent of those in assisted living (excluding nursing homes) are affected by either dementia or Alzheimer's disease. ${ }^{14}$ These patients may become confused during a mass violence incident, and antielopement measures can further impede their evacuation. Like many assisted-living facilities, Pinelake housed patients with cognitive decline, including 20 dedicated Alzheimer's care beds. During the shooting at the facility, staff members struggled to hide and barricade access routes to these especially vulnerable patients. During a mass violence event at a facility housing the frail elderly, it is probable that substantial physical and cognitive challenges for patients to implement self-protective actions will be encountered. Staff members or responders will likely be required to assist in protecting these patients. At Pinelake, this resulted in staff members being placed in harm's way and one nurse being killed while attempting to protect patients. ${ }^{4}$

\section{Evacuation and Relocation}

Even if frail elders can implement protective actions, risks may persist after the shooter is subdued. Older patients have a higher risk of mortality due to penetrating trauma because most Americans over the age of 75 years have at least one chronic medical condition. ${ }^{5,15}$ If not allowed to promptly return to the facility, as may be the case during an investigation or recovery effort, these patients will need prompt sheltering and possibly maintenance treatment for their conditions. Frail elders are highly susceptible to hypothermia, hyperthermia, and dehydration. Deaths due to these causes have been noted when skilled nursing facilities have been evacuated. ${ }^{16,17}$

During a sustained evacuation because of an active shooter, facility staff may not be mentally or emotionally able to continue caring for patients, thus requiring additional medical personnel to monitor patients and administer maintenance medication. If another option is not immediately available, many of these patients may require transport to a local hospital. These hospitals are at a high risk of medical surge owing to the influx of trauma victims from the event and may lack resources to care for a large influx of uninjured but potentially medically complicated patients from the facility. Furthermore, evacuating elderly patients to a different health care facility has been associated with an increase in mortality. ${ }^{18}$ Moore Regional Hospital, the community hospital servicing Pinelake Health and Rehab facility, housed a total of 350 beds at the time of the incident and could have 
been easily overwhelmed had all the Pinelake patients been transported to the facility. ${ }^{4}$ Fortunately, during the Pinelake incident, conditions allowed the uninjured patients to remain onsite and be cared for by staff during the investigation and recovery efforts. While keeping patients onsite is the preference, accomplishing this requires a high degree of cooperation with law enforcement investigators. In certain circumstances, this may not be practical.

\section{Reunification}

The rapid evacuation of elderly patients from a care facility and transport to local hospitals or other nearby facilities presents unique challenges with family reunification. These rapidly evacuated patients may not have identification and some may possess cognitive impairments, thus decreasing their ability to accurately share emergency contact information. Furthermore, only $61 \%$ of those over 80 years of age own a cell phone, ${ }^{19}$ and this number is potentially lower among those in institutional living facilities. Uninjured patients may not be able to independently contact family members and inform them that they are safe as would be expected with younger populations. All of these factors will increase the burden on the family reception center. After the Carthage incident, a family reception center was heavily utilized to field dozens of calls from family members living up and down the East Coast. ${ }^{5}$ Mass violence events involving the frail elderly mandate that a well-staffed family assistance center be prioritized early in the incident. Modern media allows for family members all over the globe to know of an incident within minutes of it occurring, and calls from concerned family members should be anticipated and handled appropriately.

\section{CONCLUSION}

Mass violence targeting frail elders presents a host of challenges to emergency planners and responders. Although these events are rare, the Pinelake Health and Rehab shooting exhibits their deadly potential even when the most efficient response practical by local authorities is carried out. Eldercare facilities are a ubiquitous vulnerability in communities in our country and could be further exploited by domestic or foreign terrorist organizations or lone attackers in the future. Many eldercare facilities maintain disaster plans; however, these plans should be reviewed to ensure hostile-action-based threats are adequately considered. Furthermore, local authorities should prepare contingencies for managing both the injured and uninjured patients resulting from senior care violence.

\section{About the Authors}

Office of Professional Development, Wake County EMS, Raleigh, North Carolina (Mr Martin), and Charlotte-Mecklenburg Emergency Management, Charlotte, North Carolina (Mr Powell).

Correspondence and reprint requests to Cody Martin, Office of Professional Development, Wake County EMS, 4011 Carya Drive, Raleigh, NC 27610 (e-mail: cody.martin@wakegov.com).

\section{REFERENCES}

1. Fernandez LS, Byard D, Lin CC, et al. Frail elderly as disaster victims: emergency management strategies. Prehosp Disaster Med. 2002; 17(02):67-74. http://dx.doi.org/10.1017/S1049023X00000200.

2. Blair JP, Schweit KW. A Study Of Active Shooter Incidents, 2000 - 2013. Texas State University and Federal Bureau of Investigation. https:/www. fbi.gov/about-us/office-of-partner-engagement/active-shooter-incidents/astudy-of-active-shooter-incidents-in-the-u.s.-2000-2013. Published 2014. Accessed January 2016.

3. Coleman E, Renee C, Bowens B, et al, Eight dead in Carthage nursinghome shooting. WRAL. http://www.wral.com/news/local/story/4837676/. Published March 29, 2009. Accessed November 2, 2016.

4. Sulzberger AG, Binker M. Gunman kills 8 at a N. Carolina nursing home. New York Times. http://www.nytimes.com/2009/03/30/us/ 30shooting.html?_r=2\&scp=1\&sq=carthageshooting\&st=cse. Published March 29, 2009. Accessed February 14, 2016.

5. Brooks S. After action review of the active shooter response: Pinelake Health and Rehabilitation. Presented at North Carolina Emergency Management Association All-Hazards Conference; Sunset Beach, North Carolina; March 2010.

6. Smith SM, Tremethick MJ, Johnson P, et al. Disaster planning and response: considering the needs of the frail elderly. IJEM International Journal of Emergency Management. 2009;6(1):1. http:/dx.doi.org/ 10.1504/IJEM.2009.025170.

7. Pekovic V, Seff L, Rothman M. Planning for and responding to special needs of elders in natural disasters. Generations. 2007;4:37-41.

8. Lin FR, Thorpe R, Gordon-Salant S, et al. Hearing loss prevalence and risk factors among older adults in the United States. J Gerontol A Biol Sci Med Sci. 2011;66A(5):582-590. http://dx.doi.org/10.1093/gerona/glr002.

9. Mims B. Carthage shootings remembered a year later. WRAL.com. http://www.wral.com/news/local/story/7322685/. Published March 29, 2010. Accessed January 20, 2016.

10. Caffrey C, Sengupta M, Park-Lee E, et al, Residents Living In Residential Care Facilities. NCHS Data Brief. 2012;91. http://www.cdc.gov/nchs/ data/databriefs/db91.pdf. Accessed April 9, 2016.

11. Jacobs LM Jr. Joint committee to create a national policy to enhance survivability from mass casualty shooting events: Hartford Consensus II. J Am Coll Surg. 2014;218(3):476-478.e1. http://dx.doi.org/10.1016/ j.jamcollsurg.2013.11.004.

12. Stephan Y, Sutin AR, Terracciano A. "Feeling younger, walking faster": subjective age and walking speed in older adults. Age (Omaha). 2015; 37(5):86. http://dx.doi.org/10.1007/s11357-015-9830-9.

13. Giuliani CA, Gruber-Baldini AL, Park NS, et al. Physical performance characteristics of assisted living residents and risk for adverse health outcomes. Gerontologist. 2008;48(2):203-212. http://dx.doi.org/10.1093/ geront/48.2.203.

14. Plassman B, Langa K, Fisher G, et al. Prevalence of dementia in the United States: the Aging, Demographics, and Memory Study. Neuroepidemiology. 2007;29(1-2):125-132. http://dx.doi.org/10.1159/000109998.

15. Lustenberger $T$, Inaba $K$, Schnüriger $B$, et al. Gunshot injuries in the elderly: patterns and outcomes. A national trauma databank analysis. World J Surg World Journal of Surgery. 2011;35(3):528-534. http://dx.doi. org/10.1007/s00268-010-0920-7.

16. Tanigawa K, Hosoi Y, Hirohashi N, et al. Loss of life after evacuation: lessons learned from the Fukushima accident. Lancet. 2012;379 (9819):889-891. http://dx.doi.org/10.1016/S0140-6736(12)60384-5.

17. Dosa DM, Hyer K, Brown LM, et al. The controversy inherent in managing frail nursing home residents during complex hurricane emergencies. J Am Med Dir Assoc. 2008;9(8):599-604. http://dx.doi. org/10.1016/j.jamda.2008.05.007.

18. Yasumura S, Goto A, Yamazaki S, et al. Excess mortality among relocated institutionalized elderly after the Fukushima nuclear disaster. Public Health. 2013;127(2):186-188. http://dx.doi.org/10.1016/j.puhe.2012.10.019.

19. Smith A. Usage and adoption. Pew Research Center Internet Science E Tech. http://www.pewinternet.org/2014/04/03/usage-and-adoption/. Published April 3, 2014. Accessed May 6, 2016. 